\title{
Predicting supermarket sales: The use of regression trees
}

Received (in revised form): 2nd February, 2005

\begin{abstract}
Ana Lúcia Silva
graduated in Mathematics from the Technology and Science Faculty (TSF) at the University of Lisbon (NUL) and holds a Master's degree in Operational Research and Systems Engineering from Lisbon Technical University. She has taught at different universities and now works as the Market Research and GIS Manager for the supermarket chain Pingo Doce. Her research interests include optimisation and forecasting problems as well as the use of combined metaheuristics, geographical information systems (GIS) and data mining techniques.
\end{abstract}

\section{Margarida G. M. S. Cardoso}

is an assistant professor and Co-Director of the Master's programme in Market Research at the Business School at the ISCTE in Portugal. She holds a degree in Mathematics and a Master's degree as well as a PhD in Systems Engineering from Lisbon Technical University. Her research interests include multivariable statistics and machine learning methods in marketing research.

Abstract The performance of points of sale is influenced by multiple factors, including the characteristics of their external environment. The main focus of this study is the analysis of a supermarket chain store's external environment and its influence on the store's performance.

Principal components analysis is used for data reduction of store attributes (eg visibility and accessibility). A regression tree is used for stores' sales prediction and clustering. The first tree branching divides smaller and larger stores. Factors like the stores' lack of visibility and heavy road traffic contribute especially to the decrease of sales in smaller stores. Factors like the availability of public transport and the absence of a specific competitor in the neighbourhood contribute to a better performance of larger points of sale.

In addition to the insight it allowed concerning the performance of the existing stores, and notwithstanding some limitations (eg a static modelling approach is considered), the proposed tree model has been used successfully in predicting the performance of new stores.

\section{INTRODUCTION}

This paper is part of a study performed in 2002 involving a supermarket chain. Its primary goal is the search for predictors that are relevant in explaining

Margarida Cardoso Department of Quantitative Methods, Instituto Superior de Ciencias do Trabalho e da Empresa, Av. das Forcas Armadas, 1649-026, Lisbon, Portugal.

Tel: +351 217903264 ; Fax: +351217903941 e-mail: margarida.cardoso@iscte.pt the performance of the chain's points of sale. In addition, this study aims to gain some understanding concerning the relationships between relevant predictors of supermarkets' performance.

This study also intends to contribute to the management decision-making process in connection with:
— reassessment of a point of sale's performance, when competing chains open new stores in its 'area of influence';

- restructuring the layout of points of sale in order to increase their performance;

- the location of already planned new points of sale;

- possible closures of points of sale.

Simple rules and easy to use operational specifications for company decision 
making are the results expected from modelling the relationships between supermarkets' attributes and performance measures. Predictors include two types of variables: variables frequently used by the company (eg demographic data and competition data) and other variables (eg accessibility and visibility) that have never been used by the company since they are less easily quantified (although considered important in understanding stores' performance).

\section{BACKGROUND}

There are countless factors related to store performance. They range from intrinsic store characteristics and influence zone characteristics to social relations between the customer and the store brand. In regard to the factors concerning the store's influence zone, the store's competitors and their structure stand out - even though some studies present contradictory evidence: on one hand, the presence of major competitors or a large number of competitors may negatively influence the store's performance; ${ }^{1}$ on the other hand, this very characteristic may indicate a location with strong economic potential and purchase power positively influencing the store's performance. ${ }^{2}$

Other factors related to the store's zone of influence are demographic and socioeconomic - namely the number of inhabitants, family core, family income and ethnic background. All these factors are referenced in many studies as influencing the performance of the store. $^{3-6}$

The degree of urbanisation of the zone of influence is also noted as an influence on purchase behaviour, considering its direct relation to consumer mobility and population density. $^{7}$

In connection with the store's intrinsic characteristics, there is a relation between store performance and its internal environment, service level, assortment level and store promotion policy. ${ }^{8-10}$ Sinigaglia concludes that store size, being an indicator of, among others, assortment, service level and convenience, directly influences the store's performance. ${ }^{11}$

Other studies, just as interesting, refer to the social relation between the customer and the brand. They point out the influence of brand image in sales and in consumers' purchase behaviour. ${ }^{12-14}$

Less easily quantified variables (eg visibility and accessibility) are also important to consider in predicting sales. ${ }^{15,16}$

As a final reference, the Moutinho and Hutcheson study draws conclusions on the relevance of customer mobility, general satisfaction, the existence of other services, price level, the incidence of special promotions and, finally, the existence of discount plans that reward customer loyalty. ${ }^{17}$

The studies referred to above are taken into account in the following construction and selection of predictors of store performance. Naturally, the different social and economic contexts under which those studies were done are a restraint on the direct application of their results in this specific case.

\section{DATA COLLECTION AND REDUCTION}

The data used in this study concern 168 supermarkets, the full set of the chain's points of sale in 2002. The information collected about the supermarkets is classified according to the grouping procedure proposed by Curry and Moutinho. ${ }^{18}$ This typology divides the variables used to build models for retail sales into two major groups: 
Table 1: Characterisation of the external environment of the point of sale

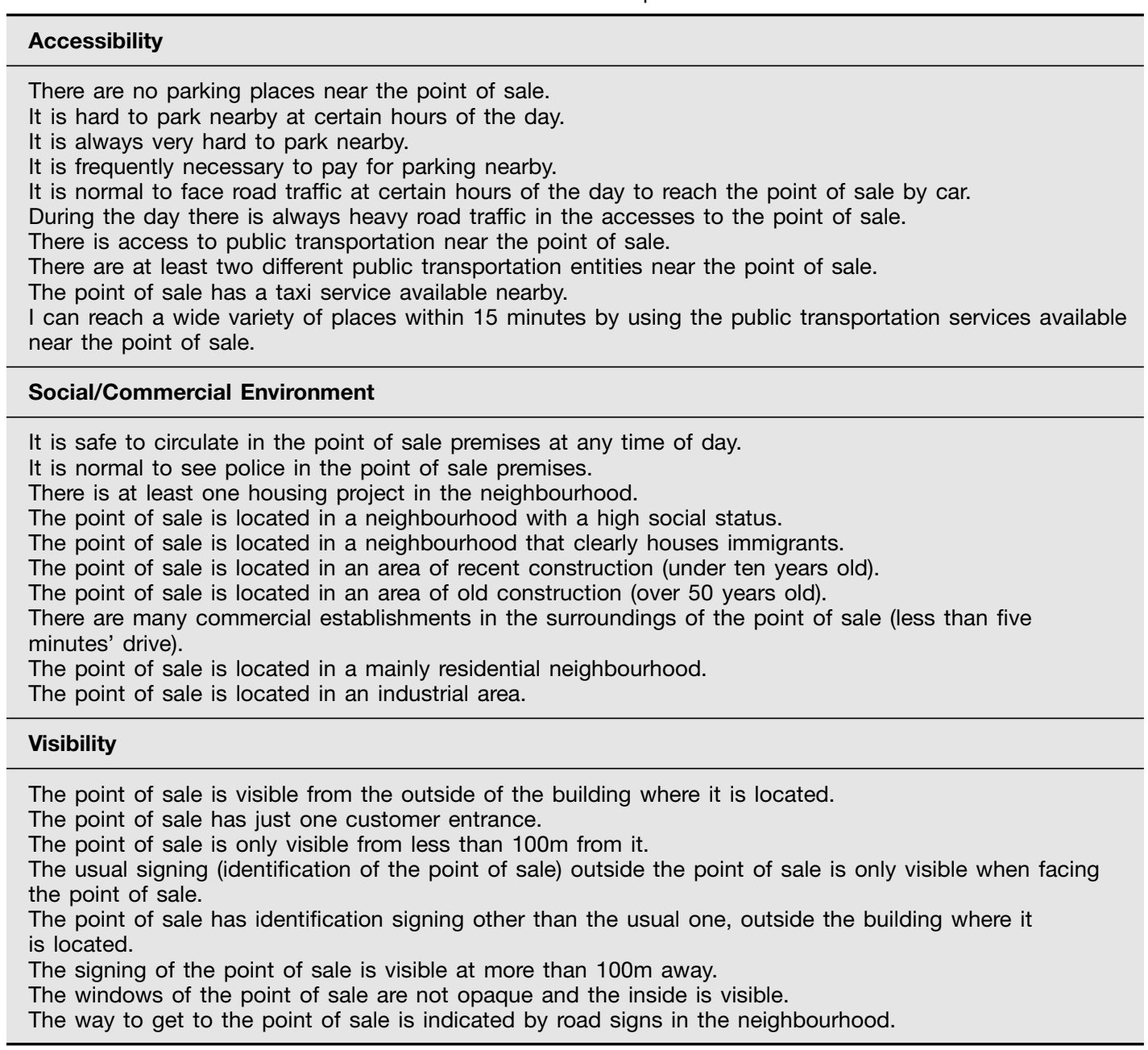

— internal variables: characteristics of the points of sale;

- external variables: characteristics of the influence area of points of sale.

The first group includes data on the physical and the interior layout characteristics of the point of sale, on the speed of service and on performance measures used in the company.

The second group includes information about the characterisation of the point of sale environment, including demographic and competition data, within a pre-defined area based on three distance rings: immediate, primary and secondary areas corresponding to five, ten and 15 minutes travel by car.

The data sources used to collect the information differ for each main group:

— internal data on the points of sale are essentially provided by the different company management boards or by the existing corporate data warehouse. The use of a customer fidelity card also helped in the collection of some specific data;

- external data on each point of sale are provided by the point of sale's management and by secondary sources such as National Statistics Institute (INE) or the Portuguese Postal Service (CTT). 
Table 2: Adequacy of the principal components analyses

\begin{tabular}{lll}
\hline & KMO & P-value (Bartlett Test) \\
\hline Accessibility & 0.78 & 0.000 \\
Social and commercial environment & 0.54 & 0.000 \\
Visibility & 0.62 & 0.000 \\
\hline
\end{tabular}

In addition, an enquiry addressed to the points of sale managers was prepared and used to collect specific information. Besides complementing data on environmental and competitor characteristics, this enquiry also provides information on the operation of each point of sale. The external variables considered in the enquiry include information related to point of sale accessibility, road traffic, parking, security, point of sale visibility and demographics. When evaluating the environment, the supermarkets' managers expressed their opinions concerning the statements included in Table 1 in a Likert scale $(1=$ totally disagree. $\ldots 5$ = fully agree $)$, thus taking into account the complex and sometimes subjective nature of this information.

After data collection, accessibility, social environment and visibility measures are subjected to principal components analysis (PCA) allowing data reduction and interpretation through the construction of new variables representing the latent concepts. ${ }^{19}$ The new variables (components) are meant to represent a large percentage of the original data total variance (meaning a small loss of information associated with data reduction) in order to be used as an input in regression (as new predictors of stores' performance).

The results referring to the adequacy of three separate PCAs - concerning accessibility, social/commercial environment and visibility - are presented in Table 2. The Kaiser Meyer Olkin (KMO) measure is greater than 0.5 and the Bartlett sphericity tests reject the hypothesis of the matrix of correlations between the original variables being the identity matrix. As a result of PCA the initial 28 variables are reduced to 13 principal components.

After using the Kaiser criterion to select the reduced number of principal components, the percentage of total variance explained by the principal components in each analysis is always greater than 67 per cent. In addition, the proportion of explained variability that refers to each of the initial variables is always high (all communalities are larger than 0.5 ).

The interpretation of the principal components retained in each analysis (based on the measures of their correlation with each one of the original variables, estimated after the VARIMAX rotation) is summarised in Table 3 (scales refer to the degree of agreement with the existence of each condition/component label).

\section{LEARNING SUPERMARKET SALES}

\section{Regression tool}

Unit sales area (per square metre), an indicator frequently used by the company, is the selected target variable, in order to model retail potential.

A preliminary analysis of the variables contained in the database concludes that the correlations between several candidate predictors and sales values per square metre are very low, usually insignificant, the linearity of the data thus being in question. Since the quality of 
Table 3: Principal components of the external characteristics (proportion of total variance explained)

\begin{tabular}{ll}
\hline & Parking conditions \\
Accessibility (67\%) & Public transportation \\
& Road traffic \\
& Building \\
Social and commercial environment $(71 \%)$ & Neighbourhood and office buildings status \\
& Commerce/Industry \\
& Housing projects and residential neighbourhood \\
& Safety \\
& Immigration \\
& Visibility conditions \\
& Advertising \\
Visibility (67\%) & Type of visibility \\
& Signing \\
\hline
\end{tabular}

the results obtained by applying regression trees with classification and regression trees (CART) algorithm is very competitive when dealing with non-linear problems or with multiple structure data, ${ }^{20}$ this approach is adopted in this application. Some additional advantages of the approach include:

— the possibility of using different types of predictor variables (continuous, ordinal or nominal);

- it is not compulsory to transform initial predictor variables (eg using logarithmic functions) since the method does not rely on strict assumptions such as normal distribution of continuous variables;

- the possibility of using the same predictor variable in different stages of the model, thus allowing interactions between predictor variables to be recognised.

Furthermore, regression tree models are very easy to interpret making them appealing from the manager's point of view. This is particularly relevant in the present application since it is expected to present simple rules and operational specifications that may easily be taken into account in the company's decisions. Finally, the use of regression trees in this first exploratory approach, aimed at explaining the points of sale performance, may also be seen as a starting point for the use of predictive probabilistic models.

\section{CART algorithm}

CART methodology relies on binary recursive partitioning of the base data for the construction of a regression tree. The tree is built from the data set gathered in the root tree node. Each node is split into two descending nodes using a splitting variable (one of the predictor variables). The selection of the splitting variable searches for the decreasing of the within-nodes variability and for the increasing of between nodes variability, each partition obtained producing a tree with less variability than the immediately preceding tree. Although it is possible to develop a maximal tree (reaching its maximum depth, not being able to grow any further) it is convenient to restrain tree growth through the definition of stopping rules, to avoid overfitting the model base data. The stopping rules used in this application, concerning the restriction of the number of observations that a parent node or a child node may contain, were two and one, respectively. A minimum quality improvement of 
Table 4: Candidate predictors for the regression tree model

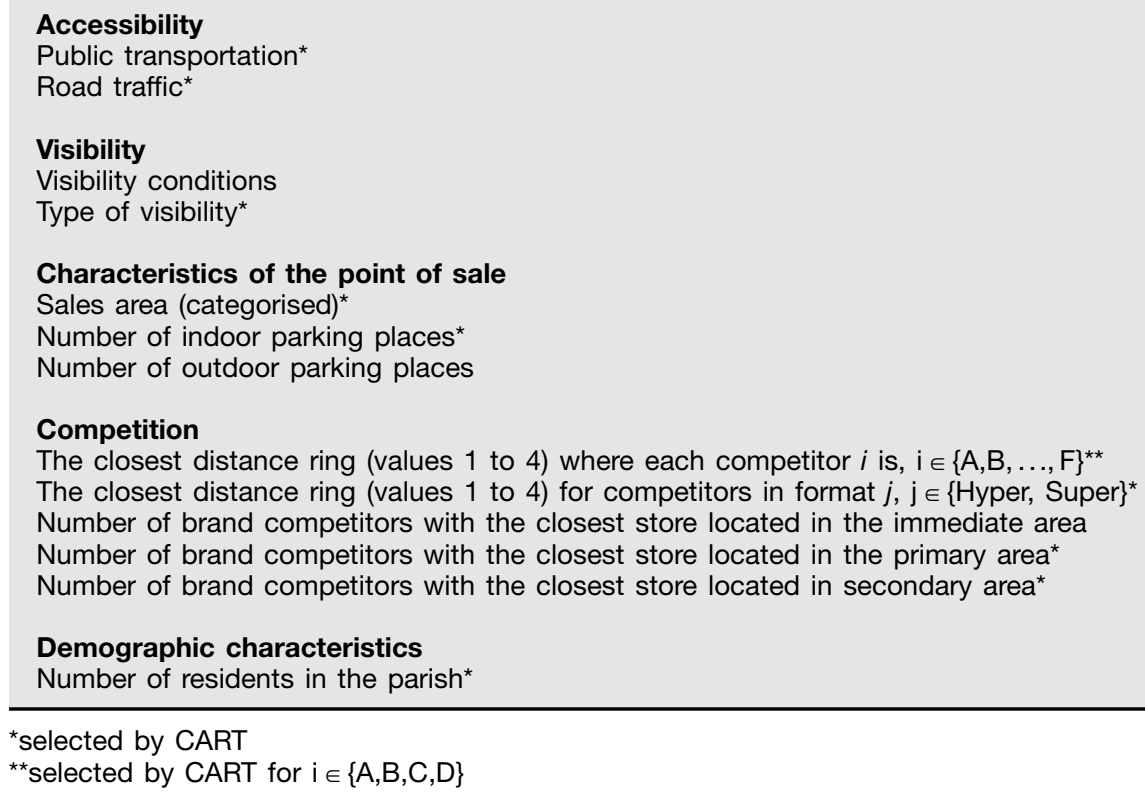

0.0001 (minimum decrease registered in the sales variance resulting from branching) was also imposed. Finally, a maximum depth of seven levels was considered.

A cost-complexity based pruning process may also be used in the CART algorithm to avoid tree overfitting. This criterion represents the balance between the accuracy of the tree-based predictions and its complexity. The model complexity decrease increases its generalisability and will also make the model more interpretable.

The prediction is finally assessed in each terminal node of the tree using the average calculation of the target variable.

In order to obtain reliable error estimates associated with the proposed regression tree it should be tested on clean data (ie not the same data that have been used to build the tree). Since the number of points of sale is not very large, a cross-validation approach (tenfold) was adopted for the present application.

\section{The regression tree model}

As already mentioned the target variable is the sales value per square metre of the points of sale. After some initial trials (in which several regression trees were built) a list of 19 candidate predictor variables was considered for the present application (see Table 4). Many of the variables relevant for the prediction of the performance of the points of sale do, in some way, mask the importance of other predictors. The existence of relations between the variables used to explain the sales per square metre leads to ties, or very close ties, in the selection of the branching predictors, the CART's selection falling upon variables that may, somehow, be misleading, making model interpretation difficult. Attempting to deal with this problem, the analyst-expert intervention allowed the selection of candidate predictors when quasi-ties were found. ${ }^{21}$

As an additional result of this 'trial and error' phase, it was decided to categorise the variable sales area in a seven-point 
Table 5: Regression tree model (first two levels)

\begin{tabular}{ll}
\hline Level 1 & Level 2 \\
\hline $\begin{array}{l}\text { Node } 1-\text { Number of points of sale }=47 \\
\text { Sales area } \leq 551 \mathrm{~m}^{2} \\
\text { I Sales } / \mathrm{m}^{2}=123.0\end{array}$ & $\begin{array}{l}\text { Node } 3-\text { Number of points of sale }=12 \\
\text { Type of visibility } \leq-1.06 \\
\text { I Sales } / \mathrm{m}^{2}=87.8\end{array}$ \\
& $\begin{array}{l}\text { Node } 4-\text { Number of points of sale }=35 \\
\text { Type of visibility }>-1.06 \\
\text { I Sales } / \mathrm{m}^{2}=135.0\end{array}$ \\
$\begin{array}{l}\text { Node } 2-\text { Number of points of sale } 5121-\text { Number of points of sale }=59 \\
\text { Sales area }>551 \mathrm{~m}^{2}\end{array}$ & $\begin{array}{l}\text { Nodersity in public transportation }<0.032 \\
\text { I Sales } / \mathrm{m}^{2}=91.1\end{array}$ \\
& $\begin{array}{l}\text { I Sales } / \mathrm{m}^{2}=77.8 \\
\text { Node } 6-\text { Number of points of sale }=62 \\
\text { Diversity in public transportation }>0.032 \\
\text { I Sales } / \mathrm{m}^{2}=103.7\end{array}$ \\
\hline
\end{tabular}

scale, as the CART algorithm consistently suggested this categorisation. Thus, 47 points of sale are classified as small stores (under level 3, meaning $551 \mathrm{~m}^{2}$ ) and the remaining 121 points of sale (classified from four to seven on the proposed scale) represent larger stores.

The selection of the tree model was finally made using the cross-validation error estimate (30 per cent of sales variance remained unexplained).

The regression tree obtained includes several predictor variables, namely the principal components of accessibility and visibility, the characteristics of the points of sale, competition variables and also demographic characteristics (see Table 4). Most variables selected by CART (13 predictors) refer to the characterisation of the surrounding of the points of sale.

\section{Model evaluation and interpretation}

The tree resulting from the application of the model presents a complexity of 47 nodes and a depth of seven levels. The total number of leaf nodes is 24 .

The model explains 70 per cent of the initial variance of the sales value per square metre. This performance measure is obtained by cross-validation and illustrates the good predictive capability of the model. In order to support the tree model analysis, the tree is presented by levels and the characteristics of the points of sale included in the nodes under analysis are described. Each node is comparatively evaluated considering the assessment of the performance of all variables included in the database, the main results being summarised here.

The target variable (sales value per square metre) is represented as an index, in which each node's sales average is divided by the global average (referred to the 168 points of sale). Thus, if a variable reaches a rate of 120 in a specific node, that means an average of 20 per cent above the global one.

The first level of the tree is obtained from the branching of the points of sale using the variable sales area (see Table 5). Two subsets of points of sale are created in this branching: one of them includes the points of sale with less than $551 \mathrm{~m}^{2}$ (level 3 when referred to the sales categories that are considered), and the other includes the points of sale with more than $551 \mathrm{~m}^{2}$. The splitting of the nodes in level 1 , concerning the variable sales area, was predictable due to its strong association with sales values.

The branching in the second level is based on type of visibility and public transportation, both variables deriving from principal components analysis. 


\begin{tabular}{|c|c|c|c|c|c|}
\hline Level 1 & Level 2 & Level 3 & Level 4 & Level 5 & Level 7 \\
\hline \multirow[t]{6}{*}{ Sales area $\leq 551 \mathrm{~m}^{2}$} & $\begin{array}{l}\text { Node } 3 \\
\text { Type of visibility } \\
\leq-1.06\end{array}$ & \multirow{2}{*}{\multicolumn{4}{|c|}{$\begin{array}{l}\text { Node } 7-\text { Number of points of sale }=7 \\
\text { Road traffic } \leqslant-0.531 \\
\text { I Sales } / \mathrm{m}^{2}=103 \\
\text { Node } 8-\text { Number of points of sale }=5 \\
\text { Road traffic }>-0.531 \\
\text { I Sales } / \mathrm{m} 2=66\end{array}$}} \\
\hline & & & & & \\
\hline & \multirow{4}{*}{$\begin{array}{l}\text { Node } 4 \\
\text { Type of visibility } \\
>-1.06\end{array}$} & & \multicolumn{3}{|c|}{$\begin{array}{l}\text { Node } 15-\text { Number of points of sale }=4 \\
\text { Diversity in public transportation } \geq 0.598 \\
\text { I Sales } / \mathrm{m}^{2}=146 \\
\text { Node } 16-\text { Number of points of sale }=3 \\
\text { Diversity in public transport } \leq 0.598 \\
\text { I Sales } / \mathrm{m}^{2}=220\end{array}$} \\
\hline & & & & \multirow[t]{2}{*}{ Node 27} & $\begin{array}{l}\text { Node } 37-\text { Number of points of } \\
\text { sale }=7 \text { of residents in the } \\
\text { Number of } \\
\text { parish } \leq 14443 \\
\text { I Sales } / \mathrm{m}^{2}=68\end{array}$ \\
\hline & & & & & $\begin{array}{l}\text { Node } 38-\text { Number of points of } \\
\text { sale }=6 \text { of residents in the } \\
\text { Number of } \\
\text { parish }>14443 \\
\text { I Sales } / \mathrm{m}^{2}=118\end{array}$ \\
\hline & & & \multicolumn{3}{|c|}{$\begin{array}{l}\text { Node } 18-\text { Number of points of sale }=5 \\
\text { Closest distance ring where competitor } A \text { is }>3 \\
\text { I Sales } / \mathrm{m}^{2}=174\end{array}$} \\
\hline
\end{tabular}

Figure 1 Regression tree model (points of sale with small sales areas)

The points of sale that have a small area, included in Node 1 , find their best partitions in the variable type of visibility, differentiating the ones with visibility into their interior. The points of sale with a lower sales performance per square metre are the ones included in Node 3. These are supermarkets with no visibility into their interior and with no outside visibility,

considering the building where they are located. Most of the points of sale classified in Node 4 (with or without outside visibility) have visibility into their interior.

As to the development of the model for points of sale with a bigger area, the cut variable chosen was diversity of public transportation. This variable presents higher values for the points of sale with more accessibility by public transportation and lower values for the remaining ones. The points of sale that represent the highest sales values per square metre, classified in Node 6, are the ones served by multiple types of public transport or that, alternatively, serve a great variety of locations. The points of sale with a lowest performance (Node 5) have a bigger sales area and are served by a lowest diversity in public transportation.

Through analysis of the model corresponding to the points of sale with 
a small sales area (see Figure 1) it may be inferred that:

- the performance of the points of sale with bad visibility (with no visibility into their interior), ie Nodes 7 and 8, is directly influenced by the road traffic conditions in the surroundings, lower road traffic meaning a better performance. In fact, stores with no visibility into their interior having a high traffic volume in the surroundings, produce the worst performance result for small stores (leaf node 8);

- the points of sale with good visibility and located in areas with fewer residents (leaf node 37) have a weaker performance, suggesting the need to establish a criterion regarding a minimum number of residents.

The cut variables considered for the sub-model of the points of sale with larger sales area (see Figure 2) are the ones related to the competition (presence of competition in the surrounding area — immediate, primary or secondary, or with the presence of a specific competitor, as defined in Table 4), directly influencing the performance of these points of sale.

The leaf nodes number 11, 29, 39 and 55 refer to the points of sale with a low performance and located in sites served by a small diversity in public transportation and strongly influenced by competition. Nodes 23, 24, 34 and 43 refer to points of sale served by a good range of public transport and with a specific competitor located at a distance corresponding to less than ten minutes car travel time. The best node for bigger points of sales is leaf node 46. Those stores have good public transport access, with no disturbance due to a specific competitor and with a large number of residents in the area.

\section{MODEL IMPLEMENTATION}

The presented model is currently in use by the retail chain, fulfilling some of the proposed objectives:

- preparation of proposals for the location of future points of sale is based on all the available information, including the initial enquiry. The variables used in the enquiries are submitted to principal components analysis. The scores obtained for each component corresponding to a potential new location make it possible to determine its assignment to the respective tree node, thus predicting unit sales (per square metre) for that point of sale;

— in addition to sales prediction, the point of sale assignment to a specific tree node allows an immediate analysis of the strengths and weaknesses of its location;

- this model may also be used to analyse the area increase of the smaller points of sale. It is possible to see its classification, through a sensitivity analysis, if it is assigned to the node corresponding to sales areas larger than $551 \mathrm{~m}^{2}$ and thus support decisions concerning the expansion of a point of sale.

\section{LIMITATIONS AND PERSPECTIVES}

This paper's main objective is to present and discuss the results of a study concerning the sales impact of a supermarket chain's external characteristics. Although accounting for 70 per cent of sales per square metre variance, this model has a limitation concerning the set of predictors. In consequence, further analysis should be conducted in the near future in order to include the point of sale's internal characteristics as predictors of sales 


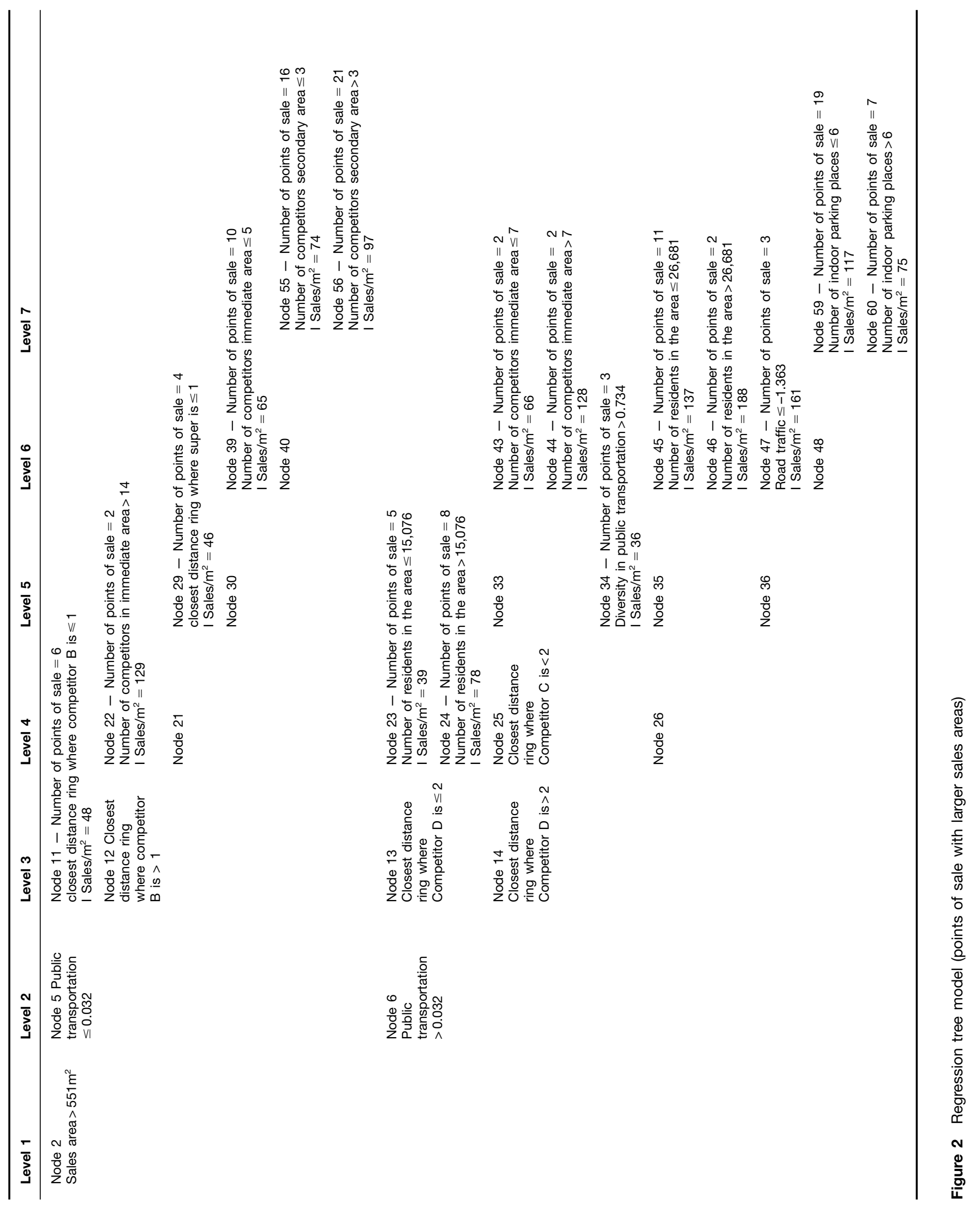


performance. This analysis should take into account the possibility of predictors masking each other, thus calling for qualitative and quantitative ways to address this problem. From a qualitative perspective the analyst-expert intervention should be formalised. In addition, measuring the relative importance of predictors may help to better understand the predictors' selection from a quantitative perspective.

Since the present model is static, its stability may be questioned. In fact, periodic adjustments of the proposed model should be made (eg concerning demographic characterisation or competition). Complementing the analysis here, a sensitivity analysis relating to the inclusion of new predictors' observations should thus be conducted in order to address this issue.

\section{References}

1 Dhar, S. K. and Hoch, S. J. (1997) 'Why store brand penetration varies by retailer', Marketing Science, Vol. 16, pp. 208-227.

2 Ingene, C. A. (1984) 'Structural determinants of market potential', Journal of Retailing, Vol. 60, pp. 37-64.

3 Dhar and Hoch (1997) op. cit.

4 Johnson, M. (1997) 'The application of geodemographics to retailing: Meeting the needs of the catchment', Journal of the Market Research Society, Vol. 39, pp. 203-224.

5 Montgomery, A. (1997) 'Creating micro-marketing pricing strategies using supermarket scanner data', Marketing Science, Vol. 16, pp. 315-337.

6 Zeithaml, V. A. (1985) 'The new demographics and market fragmentation', Journal of Marketing, Vol. 49, pp. 64-75.

7 Ingene (1984) op. cit.

8 Dhar and Hoch (1997) op cit.

9 Bell, D. R. and Lattin, J. M. (1998) 'Shopping behavior and consumer preference for store price format: Why "large basket" shoppers prefer EDLP', Market Science, Vol. 17, pp. 66-88.

10 Sirohi, N., McLaughlin, E. W. and Wittink, D. R. (1998) 'A model of consumer perceptions and store loyalty intentions for supermarket retailer', Journal of Retailing, Vol. 34, pp. 223-245.

11 Sinigaglia, N. (1997) 'Measuring retail units efficiency: A technical approach', unpublished doctoral dissertation, CREER, FUCAM.

12 Stanley, T. J. and Sewall, M. A. (1976) 'Image inputs to a probabilistic model: Prediction retail potential', Journal of Marketing, Vol. 40, pp. 48-53.

13 Dickson, J. and MacLachlan, D. L. (1990) 'Social distance and shopping behavior', Journal of the Academy of Marketing Science, Vol. 18, pp. 153-161.

14 Desmet, P. and Renaudin, V. (1998) 'Estimation of product category sales responsiveness to allocated shelf space', International Journal of Research in Marketing, Vol. 15, pp. 443-457.

15 Simkim, L. P. (1990) 'Evaluating a store location', International Journal of Retail and Distribution Management, Vol. 18, pp. 33-38.

16 Stanley and Sewall (1976) op. cit.

17 Moutinho, L. A. and Hutcheson, G. D. (2000) 'Modelling store patronage using comparative structural equation models', Journal of Targeting, Measurement and Analysis for Marketing, Vol. 8, pp. 259-275.

18 Curry, B. and Moutinho, L. (1992) 'Computer models for site location decisions', International Journal of Retail and Distribuition Management, Vol. 20, pp. 231-243.

19 Johnson, R. and Wichern, R. (1982) 'Applied multivariate analysis', 3rd edn, Prentice-Hall.

20 Breiman, L., Friedman, J., Olshen, R. and Stone, C. (1984) 'Classification and regression trees', Wadsworth, Inc., California.

21 Mendes, A. B. and Cardoso, M. G. M. S. (forthcoming) 'Clustering supermarkets: The role of experts', Journal of Retailing and Consumer Services. 